\section{PRIZE SUBJECTS OF THE PARIS SOCIÉTÉ D'ENCOURAGEMENT.}

THE June number of the Bulletin de la Socisté d'Encouragement pour l'Industrie Nationale contains the programme of prizes and medals proposed by the Society for I9OI and following years. The questions proposed for solution cover a large field; omitting many which have only a local interest, the chief problems suggested as prize subjects for I9OI are as follows. In Mechanics, prizes of 2000 francs for a motor weighing less than 50 kilugrams per horse-power developed; for an important advance in mechanical methods of transmitting energy ; and for automobiles suitable for use in towns and in the country respectively, the conditions laid down for the motor car suitable for towns requiring the absence of fumes or smell, and in the case of the one for use in the country, only such fuel to be used as can ordinarily be obtained in country towns. In Chemistry, a prize of Iooo francs for the utilisation of any waste product ; of 2000 francs for a publication useful to chemical or metallurgical industry; two prizes of 500 francs each for scientific researches in chemistry, of which the results can be utilised in industrial work; a prize of 2000 francs for an improvement in the manufacture of chlorine; one of 1000 francs for the discovery of a new alloy useful in the arts; and of 2000 francs for a study of the expansion, elasticity, and tenacity of pottery clays and glazes, for a scientific study of the physical and mechanical properties of glass, for a new method of manufacturing fuming sulphuric acid and sulphur trioxide, and for the manufacture of a steel by the introduction of a foreign element possessing specially useful properties. In the Economical Arts, 2000 francs for an invention of new methods allowing of the utilisa. tion for lighting and heating, either for domestic or industrial purposes, of petroleum, density not less than $0.800 ; 2000$ francs for a continuous extractor; 3000 francs for a method of purifying water for domestic use; and 2000 francs for a 2-candle power incandescent electric lamp fulfilling certain special conditions.

Other prizes offered include one of 2000 francs for the best study of the diseases of cider and the means of preventing or arresting their development; of 3000 francs for the invention of a method allowing of the production of an indefinite number of positives in colours either by a direct method or with a Lippmann negative; of 2000 francs for a memoir on the silk industry in the Lyons region; of 1500 francs for a memoir on the cycle industry; and of 3000 francs for a study of commercial syndicates.

According to the general conditions for these prizes, all memoirs must be sent in before December 3I, they must be written in the French language, and are open to persons of all nationalities.

\section{UNIVERSIT V ANU EDUCATIONAL INTELLIGENCE.}

TEACHERs in Schools of Science and Technical Schools will find a Diary and Calendar just issued by Messrs. Philip Harris and Co., scientific instrument makers, Birmingham, a convenient little pocket-book. The diary is for the year commencing on September I, and ending August 3I, Igor. The dates are given of examinations in science and technology, and memoranda referring to the days on which official papers must be sent in are brought together in a calendar. The book is thus a real vade mecum for science teachers.

THE following Saturday morning courses for teachers have been arranged by the London Technical Education Board. A course of about ten lectures on the teaching of mathematics will be given by Prof. Hudson at King's College The object of these lectures is to help those who are practically engaged in teaching, and wish to become acquainted with modern methods and improvements in order to render their teaching more effective. A course on physics will be given under the direction of Prof. W. Grylls Adams and Mr. S. A. F. White. The course will consist of practical work in the Wheatstone Laboratory, the object of the instruction being to enable students to obtain an intimate knowledge of the methods employed in physical measurements and familiarity with the use of apparatus. A course of twenty lectures on physiology will be delivered by Prof. Halliburton. The object of the course is to acquaint teachers with the modern methods of teaching physiology by objective methods. A course of ten lectures on the teaching of physical geography, each lecture followed by a class for practical work, will be given by Miss Catherine A. Raisin, D.Sc., at Bedford College.

THE London Technical Education Board makes provision for advanced students as well as for those of elementary grades. During the coming session evening science courses will be held in connection with the Board at University College, King's College, and Bedford College. At University College, Prof. J. A. Fleming, F.R.S., will give a course of ten lectures, followed by laboratory practice, in advanced, electrical measurements. A course of lectures on the electric motor and its application in electric traction will be given by Prof. C. A. Carus-Wilson, each lecture to be followed by an experimental demonstration or by a class for the practical working of numerical examples in connection with the subject. A course will be given by Prof. E. Wilson, at King's College, on direct and alternating currents. In mechanical engineering, Prof. T. Hudson Beare will give a course of ten lectures, at University College, on the theory of steam engines and boilers, with laboratory work on the testing of steam engines and boilers. Prof. Beare will also give a course of five lectures on the theory of gas and oil engines, combined with laboratory work. A course of five lectures on water-tube boilers will be given by Mr. Leslie Robertson. A course will be delivered by Prof. D. S. Capper and Mr. H. M. Waynworth in the mechanical engineering laboratories of King's College. The course will consist of about twenty demunstrations upon steam and gas engines and general laboratory work. The latter portion of each evening will be devoted to experimental and practical work in the engineering laboratory in illustration of the lectures. A course on civil engineering will be delivered by Prof. Robinson. The methods of producing artificial cold will be the subject of a course of lectures to be delivered at University College by Dr. W. Hampton. At the same college, Mr. E. C. C. Baly will deliver eight lectures dealing with the methods of spectroscopy, especially in connection with the photography of the spectrum.

Her MaJesty's Commissioners for the Exhibition of $\mathrm{I}{ }_{5} \mathrm{I}$ have made the following appointments to Science Research Scholarships for the year 1900, on the recommendation of the authorities of the respective universities and colleges. The scholarships are of the value of $150 \%$. a year, and are ordinarily tenable for two years (subject to a satisfactory report at the end of the first year) in any university at home or abroad, or in some other institution approved of by the Commissioners. The scholars are to devote themselves exclusively to study and research in some branch of science, the extension of which is important to the industries of the country. A limited number of the scholarships are renewed for a third year where it appears that the renewal is likely to result in work of scientific importance. The new scholars and their nominating institutions are as follows:C. E Fawsitt, B.Sc. (University of Edinburgh), V. J. Blyth, M.A. (University of Glasgow), J. Moir, M.A., B. Sc. (University of Aberdeen), W. M. Varley, B.Sc. (Yorkshire College, Leeds), J. C. W. Humfrey, B.Sc. (University College, Liverpool), S. Smiles, B.Sc. (University College, London), N. Smith, B.Sc. (Owens College, Manchester), L. L. Lloyd (University College, Nottingham), Alice Laura Embleton, B.Sc. (University College of South Wales and Monmouthshire, Cardiff), J. A. Cunningham, B.A. (Royal College of Science, Dublin), W. S. Mills, B. A. (Queen'sCollege, Galway), J. Patterson, B.A. (University of Toronto), W. C. Baker, M.A. (Queen's University, Kingston, Ontario), J. Barnes, M.A. (Dalhousie University, Halifax, Nova Scotia), J. J. E. Durack, B.A. (University of Sydney). Seventeen scholarships granted in 1898 and 1899 have been continued for a second year on receipt of a satisfactory report of work done during the first year. The names of the scholars and the places where they are studying are as follows :-I. C. Irvine, B.Sc. (University of Leipzig), H. L. Heathcote, B. Sc. (University of Leipzig), Winifred Esther Walker, B.Sc. (University College, London), F. W. Skirrow, B.Sc. (University of Leipzig), C. G. Barkla, B.Sc. (Cavendish Laboratory, Cambridge), Harriette Chick, B.Sc. (Thompson-Yates Laboratories, University Colleye, Liverpool), F. A. Lidbury, B.Sc. (University of Leipzig), W. Campbell, B.Sc. (Royal College of Science, South Kensington), L. Lownds, B.Sc. (University of Berlin), J. T. Jenkins, B.Sc. (University of Kiel and Biological Institution,

No. 1607 , VOL. 62] 
Heligoland), R. D. Abell, B.Sc. (University of Leipzig), W. Caldwell, B.A. (University of Wiirzburg), W. B. McLean, B.Sc. (Owens College, Manchester), B. D. Steele, B.Sc. (University of Breslau), E. J. Butler, M.B. (University of Freiburg), J. W. Mellor, B.Sc. (Owens College, Manchester), L. N. G. Filon, M.A. (King's College, Cambridge). Four scholarships granted in 1898 have been exceptionally renewed for a third year. These scholars and their places of study are :Dr. A. H. Reginald Buller, B.Sc. (University of Munich), H. T. Calvert, B.Sc. (University of Leipzig), R. L. Wills, B.A. (Cavendish Laboratory, Cambridge), E. H. Archibald, M.Sc. (Harvard University).

\section{SCIENTIFIC SERIALS.}

American Journal of Mathematics, vol. xxii. No. 3.On continuous binary $\Lambda$ linearoid groups, and the corresponding differential equations and $\Lambda$ functions, by $\mathrm{E}$. J. Wilczynski. In a previous paper (vol. xxi. 2) the writer has shown that, corresponding to every group of the form

$$
\eta_{i}=\sum_{k=1}^{m} \phi_{i k}\left(x ; a, \ldots a_{r}\right) y_{k}(\mathrm{I}),
$$

where the $r$ parameters $a_{i}$ are essential, there exists system of differential equations of order $r$, whose general solutions are given by $(\mathrm{I})$, if $y_{1}, \ldots y_{n}$ form a fundamental system. The functions $\phi_{i k}$ were supposed to be uniform functions of $x$, and it was found that, if the parameters $\alpha_{i}$ were properly chosen, $\phi_{i k}$ were uniform functions of the parameters also. In the present paper he discusses these groups, the corresponding differential equations, and their solutions for the case when $n=2$. Dr. Lovett, in his note on a property of lines in $n$ dimensional space, working on the lines of Cesaro's "Lezioni di Geometria Intrinseca," shows that a line of multiple curvature cuts its osculating space of highest dimensions, or lies wholly on one side of that.space, according as the number of dimensions of the space necessary to the existence of the curve is odd or even. -Concerning the cyclic sub-groups of the simple group $\mathrm{G}$ of all linear fractional substitutions of determinant unity in two non homogeneous variables with coefficients in an arbitrary Galois field, by Dr. L. E. Dickson (read before the Chicago section of the Mathematical Society, December 1899), leads to a generalisation to the $\mathrm{GF}\left[p^{n}\right]$ of results due to Prof. W. Burnside ("On a Class of Groups defined by Congruences," Proc. of London Math. Soc, vol. xxvi.). Variations from Burnside's method of treatment are introduced, partly to avoid the separate treatment of the cases $d=1$ and $d=3$, and to take in the exceptional cases $p=2$ and $p=3$, and to reduce the calculations; and further, on the other hand, to amplify some of the proofs. A few errors are also pointed out and amended.-On some invariant scrolls in collineations which leave a group of five points invariant, by V. Snyder. The writer gives numerous references to memoirs in which the quadric surfaces which are left invariant by cyclical collineations have been exhaustively treated. There is another simple series of scrolls, viz. those contained in a linear congruence, which have not been considered, except one form noticed by Ameseder. The writer confines his attention to such surfaces. There are six collineations which are of essentially different type, which project a set of five points into themselves without leaving every point invariant. In the notation of substitution-groups these may be thus represented:

$$
\begin{gathered}
\mathrm{T}_{2} \equiv\left(\mathrm{A}_{1} \mathrm{~A}_{2}\right)\left(\mathrm{A}_{3}\right)\left(\mathrm{A}_{4}\right)\left(\mathrm{A}_{5}\right), \\
\mathrm{T}_{3} \equiv\left(\mathrm{A}_{1} \mathrm{~A}_{2}\right)\left(\mathrm{A}_{3} \mathrm{~A}_{4}\right)\left(\mathrm{A}_{5}\right), \\
\mathrm{T}_{4} \equiv\left(\mathrm{A}_{1} \mathrm{~A}_{2} \mathrm{~A}_{3}\right)\left(\mathrm{A}_{4}\right)\left(\mathrm{A}_{5}\right), \mathrm{T}_{5} \equiv\left(\mathrm{A}_{1} \mathrm{~A}_{2} \mathrm{~A}_{3}\right)\left(\mathrm{A}_{4} \mathrm{~A}_{5}\right), \\
\mathrm{T}_{6} \equiv\left(\mathrm{A}_{1} \mathrm{~A}_{2} \mathrm{~A}_{3} \mathrm{~A}_{4}\right)\left(\mathrm{A}_{5}\right) \text { and } \mathrm{T}_{7}=\left(\mathrm{A}_{1} \mathrm{~A}_{2} \mathrm{~A}_{3} \mathrm{~A}_{4} \mathrm{~A}_{5}\right) .
\end{gathered}
$$

-On the reduction of hyperelliptic integrals $(p=3)$ to elliptic integrals by transformations of the second and third degrees, by W. Gilespie. The point of the paper is an application of cubic involution to the problem of the reduction to elliptic integrals, of hyperelliptic integrals of genus $p=3$ and of the first kind, by a rational transformation of the third degree. It is a continuation of Prof. Bolza's researches on the cubic transformation ("Die Cubische Involution und Dreitheilung, \&c.," and "Zur Reduction Hyperelliptischer Integrals, \&c.," Math. Ann., Bd. 5o, pp. 68 and 3 I 4 ). - The closing paper, by Dr. E. H. Moore, was read before the American Mathematical Society at the Buffalo meeting of the summer of 1896 , and is entitled "The Cross-ratio Group of $n$ ! Cremona Transformations of Order $n-3$ in Flat Space of $n-3$ Dimensions."

Bulletin of the American Mathematical Society, July.Some remarks on tetrahedral geometry, by Dr. Timerding, is a paper read at the June meeting. Several properties of a tetra. hedral complex are given, viz. the pole curves of such a complex of lines form again another such complex among the cubic space curves circumscribed about the fundamental tetrahedron, the complex curves of such a complex of lines form another tetrahedral complex, \&c.-Prof. H. B. Newson's paper on singular transformations in real projective groups was read at the April meeting. It treats of transformations in real projective groups which can not be generated from the real infinitesimal transforma tions of certain continuous groups. The discussion, which is limited to one and two dimensions, can be readily extended to three and higher dimensions. - Miss Schottenfels, in a paper read at the June meeting, writes on groups of order $8 ! / 2$, and gives a simple proof of a correspondence established by $\mathrm{Dr}$. Dickson (Proc. of London Math. Soc., vol xxx.).-Prof. F. S. Woods continues his notes on Lobachevsky's geometry.-Prof. Pierpont reviews H. Burkhardt's "Functionen-theoretische Vorlesungen" (vol. ii. " Elliptische Functionen"). - A " correction," notes, new publications, list of papers read before the Society, with references to the places of their publication, and a full index, complete the sixth volume of the second series.

Annalen der Physik, No. 7.-Dispersion of electricity in air, by J. Elster and IH. Geitel. Since the sun's rays contain ultraviolet light before they impinge upon the atmosphere, this light must ionise the upper strata, and the ions produced will be gradually distributed through the whole of the atmosphere by diffusion and convection. Hence the atmosphere will contain stray ions of both signs, but chiefly negative ones in the lower strata, owing to their superior mobility. The presence of these ions can be made evident by an electroscope. - Influence of slight impurities upon the spectrum of a gas, by P. Lewis. Very small quantities of hydrogen and nitrogen considerably affect the spectra of helium and argon, but the reverse is not the case. Fluorescence and phosphorescence in the electric discharge through nitrogen, by P. Lewis. When nitrogen prepared from ammonium nitrate and sulphate, and purified over hot copper is pumped through an $\mathrm{H}$-shaped vacuum tube, the whole wall of the tube shows a brilliant fluorescence lasting a few seconds, which extends for a length of about a yard into the supply and exhaust tubes. The light can be made permanent by keeping the pump at work and thus supplying a continuous stream of fresh nitrogen. Spectroscopic examination shows that the fluorescence is dependent upon the presence of a number of bands in the extreme ultra-violet, due to a combination of nitrogen with a trace of oxygen. - Production of very high notes by Galton's whistle, by M. T. Edelmann. The author gives tables for the pitches of pipes of various dimensions, and instructions how to test the pipes by Kundt's dust figures. He has succeeded in constructing a pipe of only $2 \mathrm{~mm}$. diameter, which gives the enormously high pitch of 170,000 complete vibrations per second, or over two octaves beyond the extreme limit of audibility.-The magnetic force of the atoms, by R. Lang. Magnetisn is accounted for by the revolutions of negative about positive electrons. - The air thermometer at high temperatures, by L. Holborn and A. Day. The authors further investigate the properties of the air thermometer consisting of a platinum-rhodium vessel filled with nitrogen, and compare its indications with that of a platinium-iridium thermo-couple, paying particular attention to their regular expansion of the vessel. The corrected value for the melting point of gold is $1064^{\circ} 0^{\circ} \mathrm{C}$. - Difference of temperature between the surface and the interior of a radiating body, by F. Kurlbaum. A method is given of determining this difference of temperature by means of two bolometers exposed symmetrically to different surfaces of the same black partition.

\section{SOCIETIES AND ACADEMIES \\ LONDON.}

Royal Society, June I4.- "Data for the Problem of Evolution in Man. V. On the Correlation between Duration of Life and the Number of Offspring." By Miss M. Beeton, G. U. Yule, and Karl Pearson, F.R.S., University College, London.

NO. I607, VOL. 62] 